\title{
Art as a language to represent Science: a project for Lyceum
}

\author{
S.Paoletti ${ }^{* a}$ and P. Paolucci ${ }^{b \dagger}$ \\ a INFN Firenze, Italy \\ b INFN Napoli, Italy \\ E-mail: simone.paoletti@cern.ch, pierluigi.paolucci@na.infn.it
}

Creativity is something common to many disciplines and is certainly involved in artistic and scientific thought and work. Scientists and artists are asked to see and think beyond the perceivable reality. They can imagine aspects of things and phenomena, which can only be seen from an unusual perspective: they possess vision and creativity. We found it interesting to explore similarities and differences in the way Art and Science move, using the artistic language to talk about science. This is the goal of Art\&Science across Italy, an European project organized by the Italian National Institute for Nuclear Physics (INFN) and CERN: the use of the artistic language to capture the interest in the Science of all students, regardless of their attitude towards scientific subjects or their initial knowledge, in order to represent scientific ideas and research topics through artworks. The artistic tools used by students to communicate Science can be painting, sculpture, photography, filmmaking, storytelling or other artistic languages that can be useful to tell the story they have in mind. The first step of the Art\&Science across Italy project is aimed at training students on Science and Art, while in a second phase students are asked to design and implement an artwork inspired at a specific scientific topic, chosen among the ones approached during the first phase. All artworks will take part to a local exhibition, established in either a historical-cultural centre or a museum, in each participating city. The first 10 artworks of each local competition will pass to the national phase. Selected by an international committee of experts (scientists, artists, Science communicators), the winners of the national Art and Science competition will be invited to attend a school on Art and Science at CERN, in Geneva, and in other laboratories in Italy. The first edition of the project (2016-2018) involved 3000 students, who took part in scientific seminars and worked on artistic ideas inspired by Science and research. The second edition of the project involves more than 4000 high school students from Florence, Genoa, Milan, Naples, Padua, Venice, Potenza, Matera, Pisa, Rome and Turin and will end in May 2020.

European Physical Society Conference on High Energy Physics - EPS-HEP2019 -

10-17 July, 2019

Ghent, Belgium

\footnotetext{
* Speaker.

$\dagger$ on behalf of the Art\&Science Across Italy Collaboration
} 
Which color is the Higgs boson? By virtue of their imagination, young high school students are much better off than me in answering that question, which is a call to unveil the emotional connection to Physics and to Science in general. By challenging their creativity and enabling them to have their say, we can engage students, catch their attention, bring them to make questions, look at documentation, discover what the Higgs boson is about and why it matters to them.

This is the basic idea inspiring Art \& Science Across Italy (A\&S) [1], a project organized and funded by the Italian National Institute for Nuclear Physics (INFN) and by CERN: use Art as universal language to address all students and speak of Science, regardless of their knowledge and initial attitude towards scientific subjects, engaging and challenging them to represent scientific ideas and research topics through artworks. Any sort of artistic language can be used: painting, sculpture, photography, filmmaking, storytelling or any other form of Art.

The A\&S project was born in 2015 from an idea of P. Paolucci (INFN Naples), M. Hoch (HEPHY, Wien) and A. Alexopoulos (CERN). Initially it developed in the framework of the European network CREATIONS (H2020) [2] and it is inspired by the STEAM [3] educational framework which brings Science, Technology, Engineering and Mathematics together with Art, with the goal of being more engaging, creative and naturally successful for all members of any educational system.

\section{Description of the project}

The A\&S project takes place in several cities of Italy and is addressed to high school students in the third and fourth year of their studies. It is supervised by a national scientific committee and organized by a coordination committee, which comprises High Energy Physics (HEP) scientists from the cities where the project takes place. In each city the coordination committee keeps the contacts with the high school institutes wishing to participate. A close collaboration with school institutes is of primary importance for the successful development of the program, which extends for about 18 months and can be chronologically divided into the following phases:

- Education. This phase has a duration of about six months. Students are invited to attend diverse lectures on Particle Physics, other branches of Science in general, Literature, Music and any other form of Art. They visit laboratories and other sites of cultural interest: scientific centers, museums, either in their own city or in other cities.

- Project design. The students must create teams of three and think about a project. This can be anything: pictures, sculpture, jewel, animation/movie, music, book, electronics, even table-top games. It is important that they make clear the connection of their project to the scientific themes which were visited during the education phase.

- Artwork creation. Students have about three to four months to realize their projects.

- Local exhibition. An exhibition is organized in each city; the students expose their artworks side by side to other works selected from the Art@CMS [4] collection. A jury of experts (selected from both the Art and the Science world) judges the best works; the first ten are selected to participate to the subsequent national exhibition. 
- National exhibition. This is the final exhibition where the best works from all cities are exposed. A jury selects the best pieces; the authors of the first eight works (up to 24 authors) are awarded with a master at CERN on Art and Science.

- Master at CERN. This is the last phase of the project. The selected students visit CERN and for five days attend a rich program of Science and Art seminars, hands-on sessions and visits to the experiments.

Key points of the process are:

- Creativity. The initial education phase of the project is directed at stimulating the creativity of the students, empowering them to express their view about Science.

- Team Work. It is crucial that students learn to collaborate and share ideas and personal skills. Three per team is the ideal number so ensure that all of them contribute effectively.

- Make a Project. Students have to face all steps involved in producing an artwork ready for exhibition, from sketching ideas on paper to managing the time needed for execution, material procurement, dimensions and transportation.

- Interdisciplinarity. Diverse sources of information and skills are involved in the creative process. The whole project aims at bringing students closer to Science, generating an insight about the relation between Art and Science. It is an opportunity to break the mindset barrier which still in today's society takes apart the respective methodologies and competences. Art and Science are framed as two different means to inquiry and observe the world, which share common historical roots and both of which involve abstraction and creativity.

\section{The first edition of the project}

The first edition of the A\&S project took place between 2016 and 2018, involving around 3000 students and 100 teachers of 38 high schools in five cities: Milan, Padua, Venice, Florence and Naples. More than 410 artworks were exposed in the five local exhibitions organized in prestigious locations: Museo della Scienza e dalle Tecnologia Leonardo da Vinci in Milan (12 April - $1^{\text {st }}$ May 2017), Palazzo del Casinò in Venice (4-12 July 2017), Palazzo della loggia della Gran Guardia in Padua (November 2017), Accademia delle Arti del Disegno in Florence (January 2018), Museo Archeologico Nazionale di Napoli (MANN) in Naples (March 2018). The national exhibition took place at MANN in Naples. After the award ceremony, a well attended public event (On Art and Science, with the participation of the renowned Art expert Philippe Daverio, journalist and Science communicator Marco Cattaneo, actor Edoardo Leo and INFN president Fernando Ferroni) concluded the program in Naples. All the exhibitions saw a huge number of visitors and overall the project got large exposure on the media, with more than 100 citations on local and national press and on national TV channels. The A\&S website [1] received more than 65000 visits, the Facebook and Instagram pages are now counting more than 2500 followers.

In September 2018 the winning students attended enthusiastically the master at CERN. For five days they lived inside the CERN area and formed a lively and well integrated group. They 

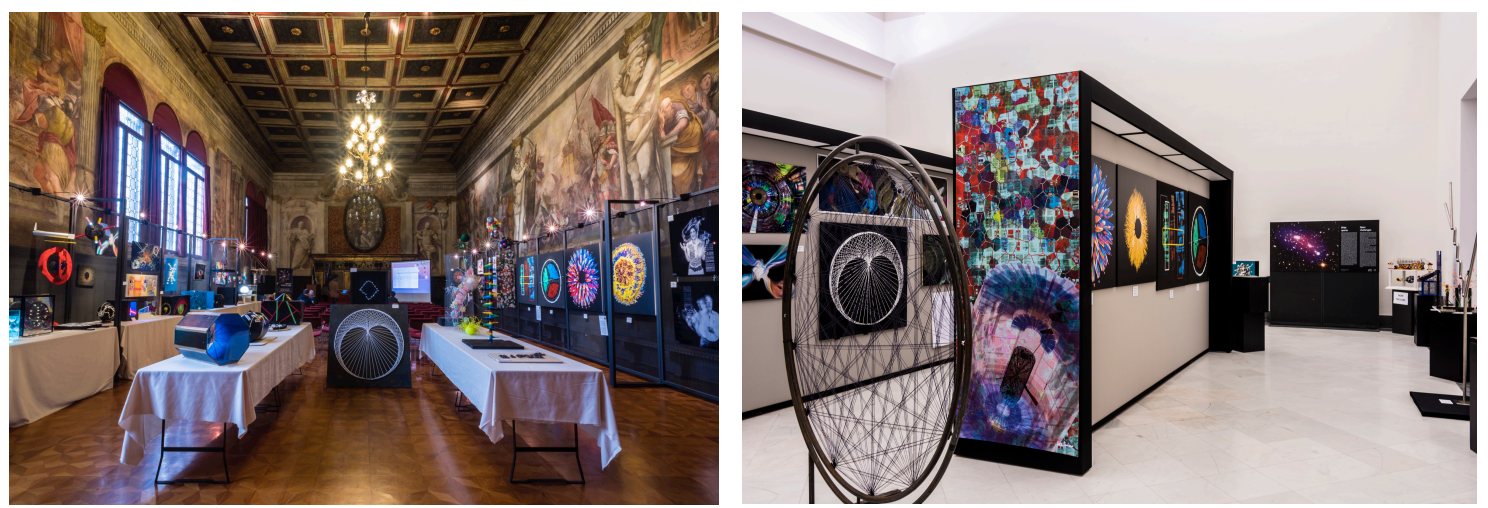

Figure 1: Left: local A\&S exhibition in Padua. Right: national exhibition in Naples.
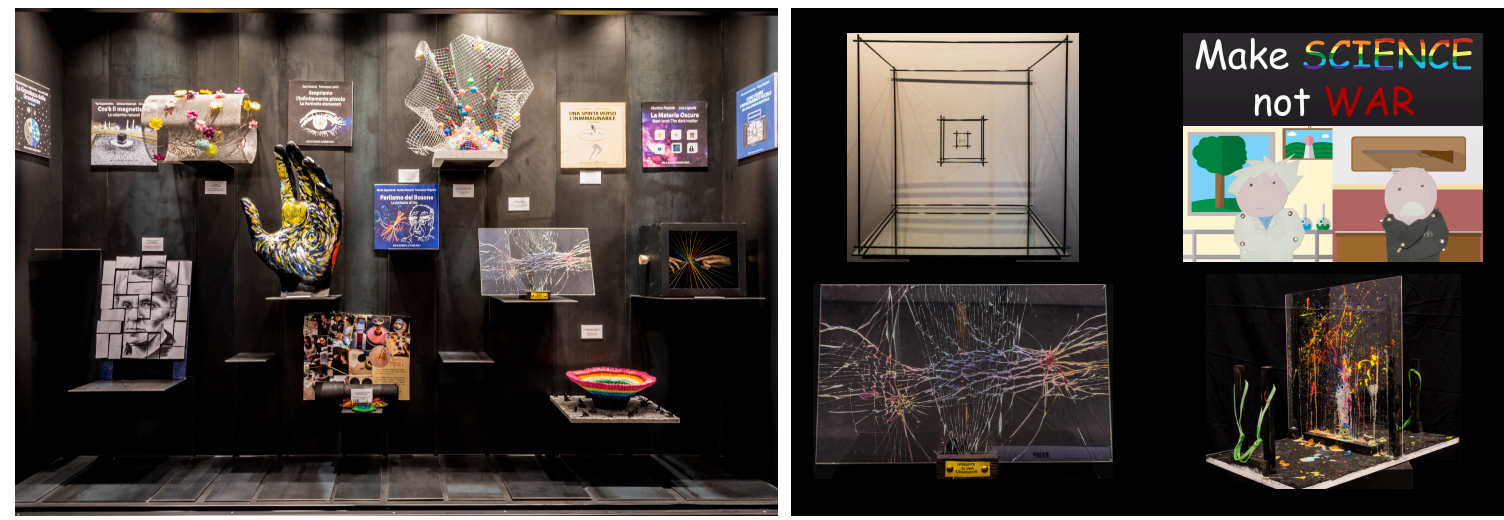

Figure 2: Artworks exposed at the national exhibition in Naples.

visited experiments, attended various lectures on the interplay between Art and Science and enjoyed the hands-on activities in the CERN's S'Cool Lab [5]: it was rewarding to observe their amazed reactions, mist of satisfaction and wonder, when they first observed particle traces showing up inside the little cloud chambers they had just assembled with their own hands !

Figure 4 shows some results from a survey performed over a sample of 700 students. Overall the project engaged to a good extent the students and it was quite well appreciated.

\section{3. the second edition}

After the success of the first edition, six more cities: Genoa, Pisa, Potenza, Matera, Rome and Turin, joined the program in the second edition (2019-20), which is currently ongoing. The first exhibition in Milan already took place in May 2019 at the Fabbrica del Vapore exhibition area and all local exhibitions are now programmed. The new edition is involving more than 4500 students from 90 high schools in 11 towns; overall 98 researches are collaborating, with the support of 21 institutional partners and 30 patronages. Figure 5 reports some statistics about gender, provenance city and school educational program.

Learning from the experience of the first edition, the number of physicists working at the project in each city has increased, in order to better distribute the efforts. This allows also to 

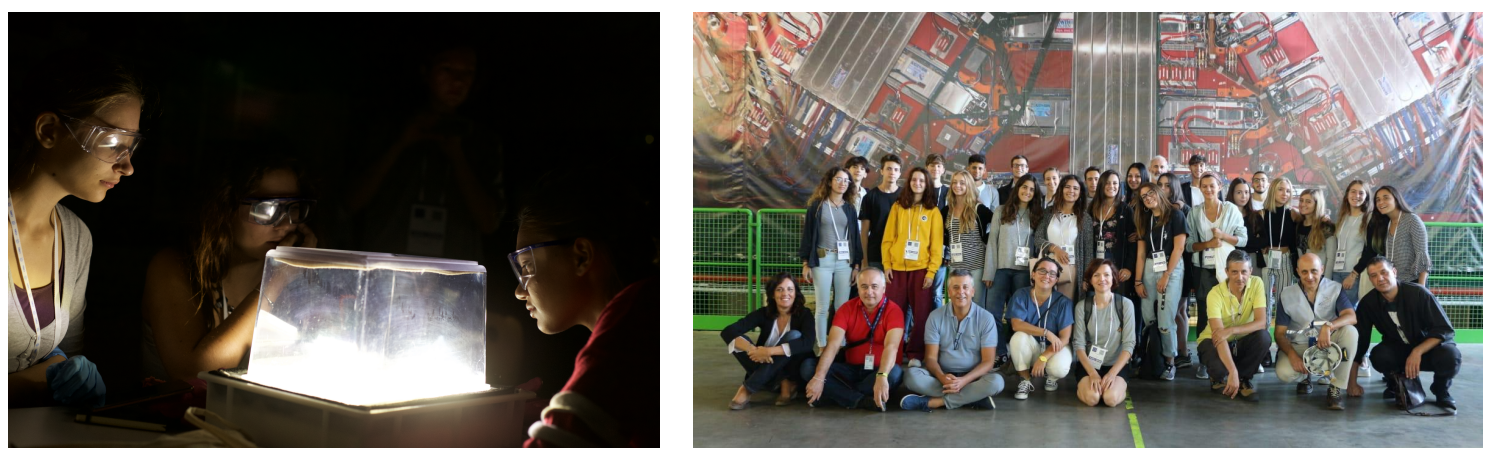

Figure 3: Images from the Master on Art\&science at CERN. Left: hands-on session at the S'Cool Lab. Right: the group visiting the CMS experiment.

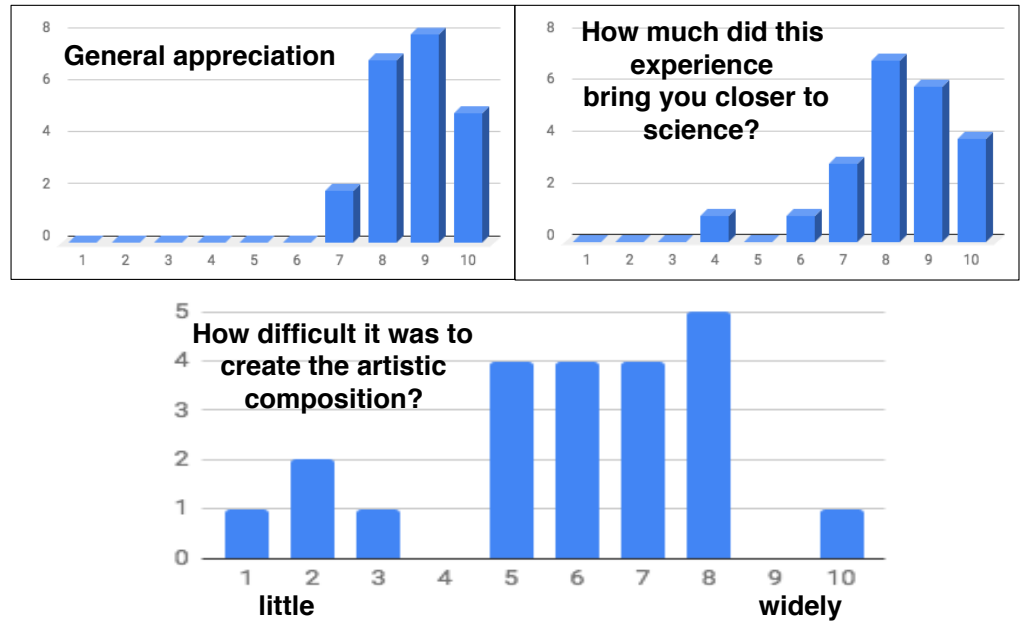

Figure 4: Results from a survey on 700 students participating to the first edition of the A\&S project. See main text for further information.

diversify and enrich the number of seminars and cultural activities offered to the students during the initial phase. Students are required to register to a portal well in advance, detailing their project, in order to more effectively collect the information and streamline the organization of the exhibitions.

\section{Summary}

The Art\&Science across Italy project is an European project organized and funded by the Italian National Institute for Nuclear Physics (INFN) and CERN. The project is addressed to high school students of several cities of Italy and it aims at bringing students closer to science, regardless of their curriculum and scientific attitude, breaking the barriers between the Art and the Science mindsets. After going through an introductory educational phase, the students have to engage in team work at the design and realisation of Art works representing Science themes of their choice.

The first edition of the project (2016-18) saw the participation of a very large number of students from five cities, unveiling the presence of a demand for this kind of activity in the education 


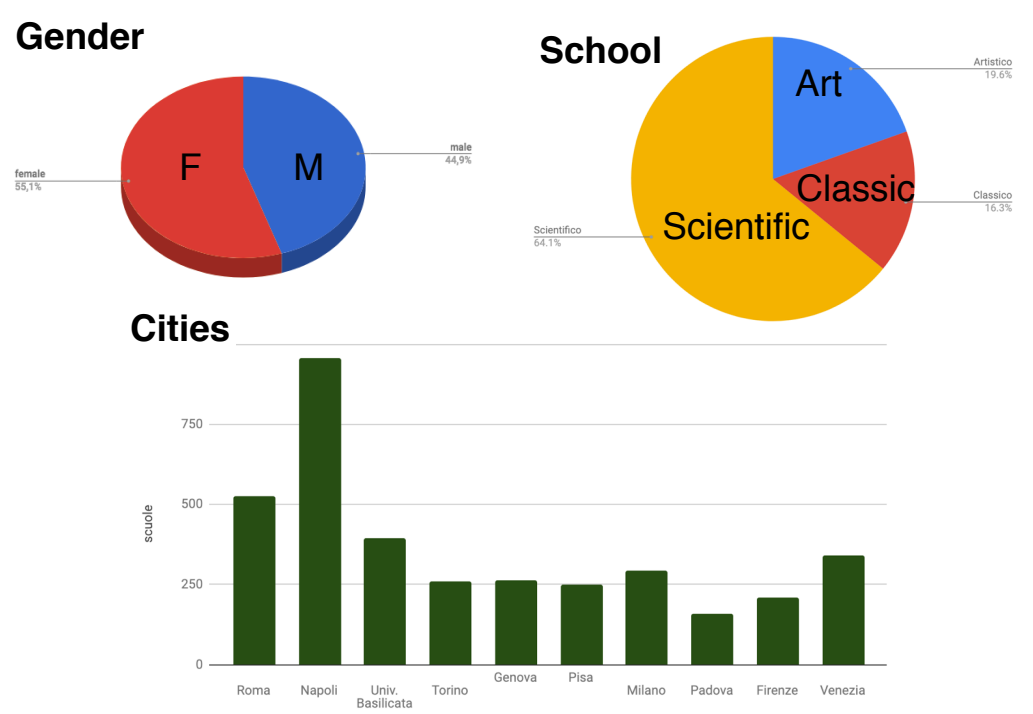

Figure 5: Statistics from a sample of students enrolling to the second edition of the A\&S project. See main text for further information.

world. Students joined quite effectively the program. The initiative received great attention and exposure in newspapers, national media and social networks. A larger number of students, with the addition of six more cities to the program, is being accounted in the second edition (2019-20) of the project, which can benefit from an enhanced organizational structure, working in the direction to establish this offer to schools on a regular basis for the years to come.

\section{References}

[1] The Art \& Science Across Italy project Home Page URL: https://web.infn.it/artandscience; Facebook page. URL: https://www.facebook.com/artandscienceacrossitaly/; Instagram page. URL: https://www.instagram.com/artandscienceacrossitaly/

[2] CREATIONS European Project. URL: http://creations-project.eu.

[3] ATLAS and CMS Collab. (P. Paolucci et al.) STEAM: Education and Communication with Art at ATLAS and CMS; PoS LHCP2016 (2016) 115; DOI: 10.22323/1.276.0115

Stem to steam project. URL: http://stemtosteam.org/

[4] Art@CMS is an education and outreach initiative of the CMS experiment at LHC. URL: http://artcms.web.cern.ch/artcms/.

[5] S'Cool Lab Physics Education Research facility at CERN. URL: https://scool.web.cern.ch. 